\title{
Towards the Effective Implementation of Collaborative Problem Solving in Undergraduate Engineering Classrooms: Co-Designing Guidelines for Teaching Assistants
}

\author{
Dr. Saadeddine Shehab, University of Illinois at Urbana - Champaign
}

A Postdoc Research Associate at the Siebel Center for Design at the University of Illinois at UrbanaChampaign; studies the role of the teacher in collaborative problem solving in STEM classrooms

\section{Dr. LuEttaMae Lawrence, University of Illinois at Urbana-Champaign}

LuEttaMae Lawrence has a PhD in Education from the University of Illinois at Urbana-Champaign in Digital Environments for Learning, Teaching, and Agency. Her background as a graphic designer inspired her interest in the design of learning environments. Her research focuses on the affordances of educational technology in formal and informal spaces and how researchers use the design process to facilitate and scaffold interdisciplinary work.

\section{Dr. Emma Mercier, University of Illinios}

Emma Mercier is an associate professor in Curriculum and Instruction at the University of Illinois UrbanaChampaign. Her work focuses on collaborative learning in classrooms, and in particular, the use of technology for teachers and students during collaborative learning. Most recently Mercier's projects have focused on collaborative learning in required undergraduate engineering courses.

Mr. Anthony Salvatore Margotta, University of Illinois Urbana-Champaign Department of Mechanical Science and Engineering

Anthony is a master's student in the Department of Mechanical Science and Engineering and former TA for TAM 251. He is helping to create resources to promote collaborative learning in undergraduate engineering courses

Elizabeth Renee Livingston

Prof. Mariana Silva, University of Illinois at Urbana-Champaign

Mariana Silva is a Teaching Assistant Professor in Computer Science at the University of Illinois at Urbana-Champaign. She has been involved in large-scale teaching innovation activities, such as the development of online course content and assessments for the mechanics course sequence in the Mechanical Science and Engineering Department and the numerical methods class in Computer Science. Silva is currently involved in two educational projects involving the development of online assessments for computerbased testing and creation of collaborative programming activities for computer science classes. She is also involved in a project that aims to create a software that facilitates collaborative problem-solving activities in classrooms, through which both the instructors and students learn more about collaboration skills. Silva is very passionate about teaching and improving the classroom experience for both students and instructors. She has been included in the List of Teachers Ranked as Excellent five times and has received the Engineering Council Outstanding Advisor Award every year since 2014.

\section{Miss Taylor Tucker, University of Illinois at Urbana - Champaign}

Taylor Tucker received her Bachelor's degree in engineering mechanics from the University of Illinois at Urbana-Champaign and is now pursuing a Master's in curriculum and instruction through the Digital Environments for Learning, Teaching, and Agency (DELTA) program. She is interested in engineering design and lends her technical background to her research with the Collaborative Learning Lab, exploring how to improve ill-structured tasks for engineering students in order to promote collaborative problem solving and provide experience relevant to authentic work in industry. 


\title{
Towards Effective Implementation of Collaborative Problem Solving in Undergraduate Classrooms: Co-Designing Guidelines for Teaching Assistants
}

\author{
Saadeddine Shehab, LuEttaMae Lawrence, Emma Mercier, Anthony Margotta, Elizabeth \\ Livingston, Mariana Silva, Taylor Tucker \\ shehab2@illinois.edu, llawrnc2@illinois.edu, mercier@illinois.edu, margott2@illinois.edu, \\ eliving2@illinois.edu, mfsilva@illinois.edu, tdtucke2@illinois.edu \\ University of Illinois at Urbana-Champaign
}

\section{Introduction}

This evidence-based practice paper presents guidelines that can be used by TAs to implement collaborative problem solving activities in undergraduate engineering classrooms. Three researchers and two engineering teaching assistants co-designed the guidelines as part of a design-based implementation research project, Collaborative Support Tools for Engineering Problem Solving (CSTEPS), that aims to develop tools to support collaborative learning in undergraduate engineering courses. This paper presents these guidelines and illustrates how TAs can use them to effectively implement collaborative problem solving activities in their future discussion sections.

\section{What is Collaborative Problem Solving?}

Collaborative problem solving can be defined as "a coordinated, synchronous activity that is the result of a continued attempt to construct and maintain a shared conception of a problem [1, p.70]". The role of the teacher in implementing collaborative problem solving activities in face-to-face STEM classrooms has received increasing attention in recent years [2], [3], [4], [5]. According to these researchers, teachers must implement strategies that can facilitate student interactions in groups which, in turn, can positively impact the group progress towards the goal of solving the task during the activity. These strategies must take place prior to the beginning of the activity, during the activity, and at the end of the activity [3]. Empirical studies that focus on examining these strategies are limited [6], [7], [8], [9]; they all recommend that teachers attend preparation programs to help them understand their role in orchestrating collaborative problem solving activities.

\section{The Role of Teaching Assistants in Collaborative Problem Solving}

Teaching assistants (TAs) are students pursuing graduate degrees and are responsible for assisting professors in teaching many higher education courses [10]. While performing their teaching duties, TAs are expected to implement various teaching practices such as presenting information, emphasizing certain concepts, communicating with students, and assessing students' outcomes [11]. Nevertheless, research has shown that TAs start their teaching positions with limited teaching experience, developing their skills by trial and error [12], and they rarely receive guidance or feedback about their teaching practices [13]. Research has also shown that TAs struggle in implementing effective strategies at the beginning, during, and at the end of a collaborative problem solving activity to support students' interactions during group work [6], [14]. Even after attending a semester-long course on how to implement collaborative problem solving, TAs struggled in translating the course content into effective teaching practices to orchestrate collaborative problem solving [15]. One reason for that can be the lack of actual 
guidelines that can help TAs translate the theoretical ideas about implementing collaborative problem solving into concrete actions [15].

Our design-based implementation research project aims at developing tools that support teachers and students during collaborative problem solving in undergraduate introductory engineering courses. In light of research that shows that TAs struggle in implementing effective strategies at the beginning, during, and at the end of a collaborative problem solving activity to support students' interactions during group work, we wanted to design guidelines that can assist TAs in orchestrating collaborative problem solving activities. We co-designed these guidelines with two engineering TAs during two workshops. This paper answers the following questions:

1) What were the co-designed guidelines for implementing collaborative problem solving that emerged from the two workshops?

2) How can TAs use these guidelines to implement collaborative problem solving activities in their future discussion sections?

\section{Methods}

\section{Design}

This work is part of a multi-year design based implementation research project [16] that focused on supporting collaborative problem solving activities in undergraduate engineering courses in a large Midwestern university. The project included the iterative co-design of tools with the teaching team (course instructors and teaching assistants) that can help the teaching assistants and students in effectively implementing collaborative problem solving in discussion sections.

\section{Participants}

Participants were three researchers and two engineering teaching assistants; one of the researchers had previously been a TA for the engineering course. The two TAs were enrolled in the master's engineering program at the university. In Spring 2019, both TAs were teaching the discussion sections of an introductory engineering course on solid mechanics. This was their fourth and fifth semesters teaching this course.

\section{Data Collection}

The team participated in two, two-hour long co-design workshops. The purpose of the workshops was to co-design guidelines that can inform future teaching assistants about implementing collaborative problem solving in discussion sections. Both workshops were audio recorded.

\section{Data Analysis}

After the workshops, two researchers went through the recordings and extracted all teaching strategies the team discussed during the workshops. All members of the team were asked to review the guidelines separately, and then met to approve and finalize the guidelines. Themes that described the creation of the guidelines were extracted from the discussions. 


\section{Results}

We created the guidelines to help TAs effectively implement collaborative problem solving in their discussion sections. Using the Implementation of Collaborative Learning in the Classroom framework [3], we discussed guidelines that can be implemented at the beginning, during, and at the end of class to support students' collaboration. During the co-design process, TAs shared that they did not think they had the leverage in their classroom to require specific collaborative behaviors from students because it was never established as an expectation from the beginning of the semester. Therefore, we started by discussing how to explicitly articulate the importance of collaboration with the students during the very first class meeting (Figure 1).

\section{IMPORTANCE OF SETTING THE STAGE}

- Stress the importance of both objectives: Learn Content + Develop Collaborative Practices during the very first class

- To create common expectations and understanding of collaboration, during the first class create two lists with the students:

1. Behaviors of Effective Groups

2. Behaviors of an Effective Individual in the Group

- Embed collaboration in assessment metrics for the course. During the first class remind students that their grade in the course is affected by their particiaption with the other group members.

Figure 1: Guidelines to structure how to emphasize the importance of discussing collaboration from the beginning of the class.

Next, we discussed research findings on the role of the teachers in implementing collaborative problem solving. The TAs shared how these matched (or mismatched) what takes place during their engineering discussion sections. Guidelines about the beginning of class were centered around how to prepare students to effectively collaborate as they solve the task (Figure 2 ). The recurring themes that emerged during this discussion were the need to remind students that they are expected to work together to solve the tasks. The students need to create a joint space to explore and test out solutions as a group; giving them details about the task-related concepts and procedures during the introductions can hinder this process. One member of the research team described this as "taking away the students" collaborative instances". 


\section{AT THE BEGINNING OF CLASS}

- Ask for students' attention

- Situate the worksheet in the scope and sequence of the course

- Provide a simple description of the task; avoid an elaborated description so the groups can explore the task together

- Explicitly present task-related and collaborative related expectations to the groups (refer to list of effective collabroative behaviors if available)
- Remind students that their grade in the discussion session is affected by their particiaption with the other group members

Avoid over explaining - allow students to ask each other and learn together

Figure 2: Guidelines for what to say at the beginning of class to promote collaboration and reiterate the importance to the students.

We spent the majority of the time in both workshops discussing guidelines related to monitoring and intervening in groups. We focused on two themes, what to look for while monitoring and how to intervene (Figure 3). We agreed on the need to monitor a group before intervening to diagnose the group's difficulties and decide if an intervention is necessary. We discussed the challenge of knowing when to intervene and when not to intervene. Research explains that sometimes when developing a joint understanding of the content, groups struggle to determine a procedure or answer [17]. However, this struggle can be productive. Providing the group with explicit problem solving procedures or answers takes away the need to co-construct knowledge [6]. Nevertheless, both TAs mentioned that sometimes it is inevitable to provide the group with an explicit explanation of a concept or a problem solving procedure. They argued that while collaboration is important, the primary goal as TAs is to help the students understand key concepts and how they are applied to real life situations. However, instead of directly explaining concepts or giving answers, we agreed to focus on asking group members to check their answers with each other. We also discussed the importance of demonstrating desired collaborative behaviors to groups and compiled a list of ways to do this. 


\section{DURING THE CLASS - AT THE GROUP LEVEL}

- Do not intervene immediately; use eyes + ears strategically

- De-emphasize the right answer; prompt students to ask their group members

Avoid providing the group with the right answer, instead say, "This looks about right, what do your team members think?"

- Prompt the groups' thought process by asking task-related questions

- Know when NOT to intervene - if goup members are discussing or working together; follow up on these groups to check if they resolved difficulty rather than providing them an immediate solution

\section{right, what do your team members think?"} 列
- Demonstrate collaborative interactions you want to see in a group such as group members questions, revoicing their answers, and actively listening

- Instruct silent groups to implement collabration-related behaviors (refer to list of effective collabroative behaviours if available); some groups will not want to collaborate, be prepared to change up groups or prompt multiple times

- Challenge students' ideas; "Can you explain why you think that?"

- Address everyone in the group when speaking, not just one group member

Figure 3: Guidelines for what to say and how to interact with groups of students as they are working.

Developing guidelines for the whole class discussions (Figure 4) and the end of class (Figure 5) were the most challenging discussions during the process of co-designing the guidelines. Neither TA had orchestrated many whole class discussions during their previous semesters of teaching. Since these are short classes, we were all wary of long whole class discussions interrupting good collaboration. We agreed that if whole class discussions are necessary they should be quick and either reiterate collaboration or quickly explain a misunderstood concept. Also, TAs did not engage in end of class wrap ups. Since this is a short class, there is often not enough time to wrap up the session and students are often ending at different parts of the worksheet. We discussed, a wrap up could be a good way to have students reflect on their collaboration or review examples of good collaboration that took place during the class. We decided that these kind of wrap up would be good during shorter worksheets and towards the beginning of the semester when there is more time and TAs are still stressing the importance of collaboration. However, there were discussions that this is a more expert skill, because TAs who are new may not have the time or capacity to keep track of who is doing well and also reflect on it at the end of class. 


\section{DURING THE CLASS - AT THE WHOLE CLASS LEVEL}

- Announce if something is wrong or unclear in the activity

- If the room seems quiet or a number of groups are off task quickly instruct the entire class to interact or get back on task

"Hey everyone, the class is a little too quiet. Just a reminder the point of this class is to work together!"
- Avoid long whole class interventions if it's not critical to accomplishing the problem solving process

- When making announcements, ask for students' attention
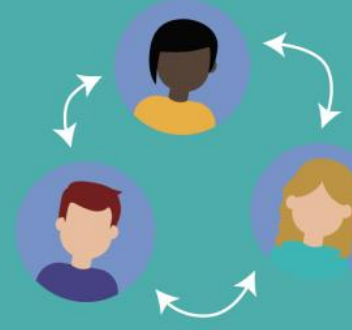

Figure 4: Guidelines of what to say and how to interact during whole class interventions.

\section{AT THE END OF CLASS}

- Share with students demos or animations to connect content to real life situations

- Discuss different groups' answers

Try asking different groups to share their answer and how they solved the problem
- Comment on moments of optimal group behavior; this requires paying attention to good examples throughout the class time

- Ask students to comment on successful collaborative instances or things they want to improve within their group

Figure 5: Guidelines of how to structure the end of class wrap up to emphasize collaboration.

During both workshops there were many discussions about how these guidelines should be shared with other TAs. Both TAs are graduating and will no longer be teaching these courses. A final decision was made to provide new TAs with a cheat sheet of guidelines for collaboration (Figures 1-5) and integrate some concrete collaborative tips based on these guidelines into the solutions pages that TAs are supplied with for each week. The TAs built these tips based on the guidelines we created as a team. Figure 6, 7, and 8 show tips that were embedded in a worksheet that future TAs can use to promote more collaboration among groups. In Figure 6, the TAs added support to help future TA situate the worksheet within the sequence of the task. Figure 7 and 8 illustrate how the guidelines, such as challenging students' ideas and transferring questions to other group members, can be embedded within challenging content areas to support the TAs when students may struggle. 
Situate the worksheet in the scope of the sequence of the course

"In this worksheet you will be combing things you've learned over the past several weeks.

Using equilibrium, constitutive relationships, and geometrical relationships, you will

determine deformation under a given loading condition and draw conclusions about its

safety.

- Sketch a free-body diagram

- Determine axial deformation based on geometry of deformation

- Evaluate a loading scenario to determine whether or not it is safe

\section{Introduction:}

Small-scale wind turbines are devices that uses the winds kinetic energy to generate electricity that can be used at remote sites, to heat homes, or to pump water. A small-scale wind turbine can be divided into three components: The rotor component that includes the blades of the turbine, the generator component, and the structural support component that includes the tower of the turbine.

Figure 6: Application of the guideline "situate the worksheet in the scope and sequence of the course"

2) Using the figure of the geometry of deformation in the Appendix:

a. Write an expression that relates the displacement of point $\mathrm{A}, \delta_{A}$, to the displacement of point $\mathrm{B}, \delta_{B}$.

b. For the deformation of each cable, $\delta_{i}$ (for $i=1,2,3,4$ ), write an expression that relates it to the horizontal displacement of the point that it is attached to (i.e. $\delta_{A}$ or $\delta_{B}$ ).

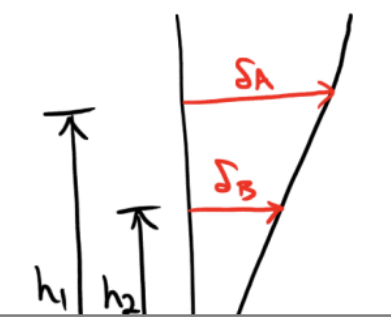

a)

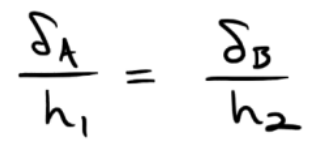

b)
Challenge students' idea

Students struggle to remember the correct way to draw the "strain triangle" below. If they've done it incorrectly, ask them if they have checked their notes and conferred with their group mates to verify that it's correct.

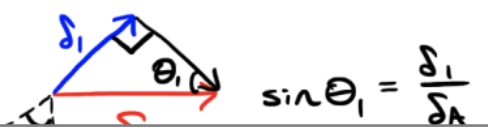

$\delta_{A}$

$\delta_{\delta_{2}} \theta_{y}$ $\sin \theta_{1}=\frac{-\delta_{3}}{\delta_{A}}$

Figure 7: Application of the guideline "challenge students ideas" 


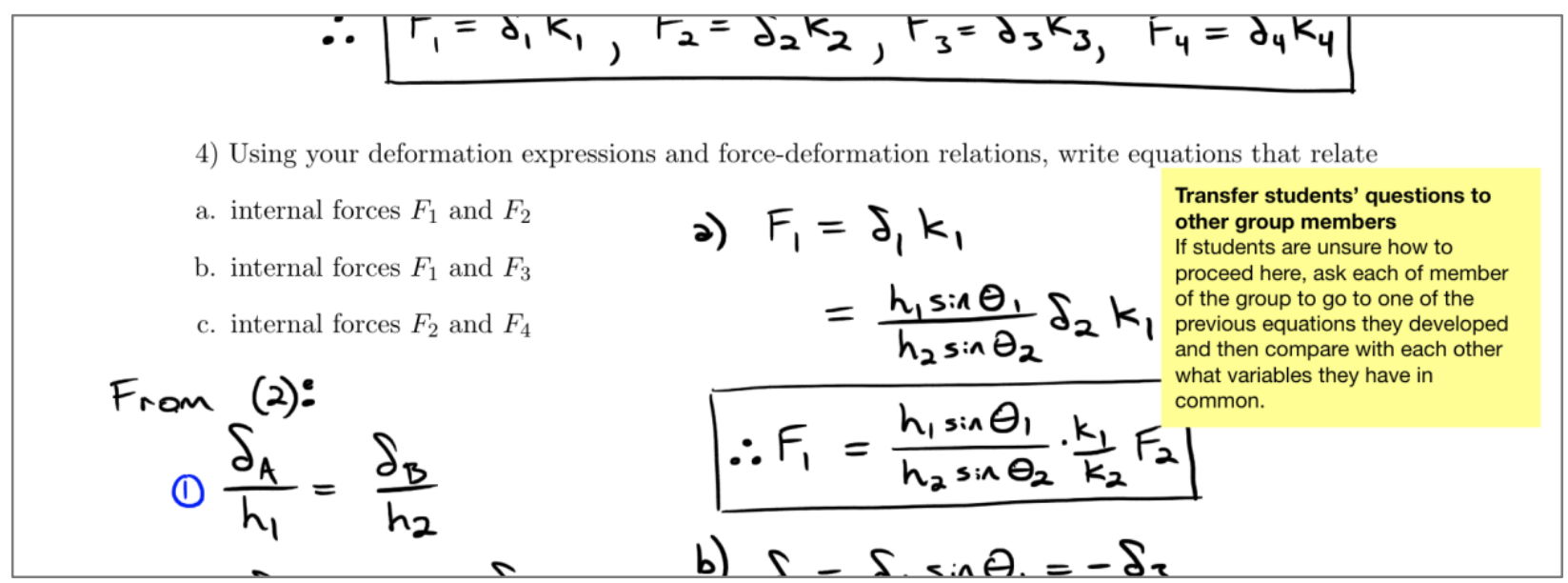

Figure 8: Application of the guideline "de-emphasize the right answer; ask prompt students to ask their group members"

\section{Conclusions and Implications}

This paper presented guidelines that can be used by teaching assistants to support students' collaboration at the beginning, during, and at the end of undergraduate engineering discussion sections. Three researchers and two TAs who had teaching experiences with collaborative problem solving co-designed these guidelines. Both TAs brought the realities of their experiences to the design process and helped shape the content and format of the guidelines in ways that can facilitate its implementation and uptake by other practitioners. These guidelines can be used to inform the content of preparation programs that aim at helping TAs better perform their teaching duties during discussion sections. They can also be used by TAs to create tips that can help them facilitate collaboration when students are working on specific worksheets. Future studies must assess the impact of using these guidelines on how TAs implement collaborative problem solving activities in undergraduate engineering classes. They must also assess the impact of using these guidelines on the TAs' perceptions of collaboration and the development of teaching practices to orchestrate collaborative problem solving classrooms. These guidelines can also be used by other teachers with different age groups and disciplines to facilitate collaborative problem solving activities.

\section{Acknowledgments}

This material is based upon work supported by the National Science Foundation under Grant No. 1628976. Any opinions, findings, conclusions or recommendations expressed in this material are those of the authors and do not necessarily reflect the views of the National Science Foundation. 


\section{References}

[1] J. Roschelle and S. Teasley, "The construction of shared knowledge in collaborative problem solving", in Computer Supported Collaborative Learning, 1995, pp. 69-96.

[2] R. Gillies, A. Ashman and J. Terwel, The Teacher's Role in Implementing Cooperative Learning in the Classroom. Boston, MA: Springer Science, LLC, 2008.

[3] C. Kaendler, M. Wiedmann, N. Rummel, and H. Spada, "Teacher Competencies for the Implementation of Collaborative Learning in the Classroom: a Framework and Research Review," Educational Psychology Review, vol. 27, no. 3, pp. 505-536, 2014. Available: 10.1007/s10648-014-9288-9.

[4] E. Mercier and S. Higgins, "The Four Ts of the Collaborative Classroom", in Computer Supported Collaborative Learning, Gothenburg, Sweden, 2015.

[5] N. Webb, "The teacher's role in promoting collaborative dialogue in the classroom", British Journal of Educational Psychology, vol. 79, no. 1, pp. 1-28, 2009. Available: 10.1348/000709908x380772.

[6] S. Shehab and E. Mercier, "Exploring teaching and course assistants' interventions with groups during collaborative problem solving," in Proceedings of the 13th International Conference of Computer Supported Collaborative Learning (CSCL), Lyons, France, June 2019.

[7] M. Chiu, "Adapting Teacher Interventions to Student Needs During Cooperative Learning: How to Improve Student Problem Solving and Time On-Task", American Educational Research Journal, vol. 41, no. 2, pp. 365-399, 2004. Available: 10.3102/00028312041002365.

[8] R. Hofmann and N. Mercer, "Teacher interventions in small group work in secondary mathematics and science lessons", Language and Education, vol. 30, no. 5, pp. 400-416, 2015. Available: 10.1080/09500782.2015.1125363.

[9] N. Webb, M. Franke, M. Ing, A. Turrou, N. Johnson, and J. Zimmerman, "Teacher practices that promote productive dialogue and learning in mathematics classrooms", International Journal of Educational Research, vol. 97, pp. 176-186, 2019. Available: 10.1016/j.ijer.2017.07.009.

[10] "Occupational Information Network", 2013.

[11] J. Luft, J. Kurdziel, G. Roehrig, and J. Turner, "Growing a garden without water: Graduate teaching assistants in introductory science laboratories at a doctoral/research university", Journal of Research in Science Teaching, vol. 41, no. 3, pp. 211-233, 2004. Available: 10.1002/tea.20004. 
[12] G. Marbach-Ad, C. Egan and V. Thompson, "Preparing graduate students for their teaching responsibilities", Springer International Publishing, 2015.

[13] S. DeChenne, N. Koziol, M. Needham, and L. Enochs, "Modeling Sources of Teaching SelfEfficacy for Science, Technology, Engineering, and Mathematics Graduate Teaching Assistants", CBE-Life Sciences Education, vol. 14, no. 3, p. ar32, 2015. Available: 10.1187/cbe.14-09-0153.

[14] S. Shehab and E. Mercier, Exploring teaching assistants' framing strategies of collaborative problem-solving engineering tasks: Learning Sciences Graduate Student Conference, October, 2018, Nashville, Tennessee.

[15] E. Mercier and S. Shehab, Adaptive expertise in the teaching of collaborative problem solving in undergraduate engineering courses: American Educational Research Association, April, 2018, New York, New York.

[16] W. Penuel, B. Fishman, B. Haugan Cheng, and N. Sabelli, "Organizing Research and Development at the Intersection of Learning, Implementation, and Design", Educational Researcher, vol. 40, no. 7, pp. 331-337, 2011. Available: 10.3102/0013189x11421826.

[17] M. Kapur and C. Kinzer, "Productive failure in CSCL groups", International Journal of Computer-Supported Collaborative Learning, vol. 4, no. 1, pp. 21-46, 2008. Available: 10.1007/s11412-008-9059-z. 